Pragmatics 8:2.239-254.

International Pragmatics Association

DOI: $10.1075 /$ prag.8.2.06gro

\title{
INTELLIGENCE AS A SENSITIVE TOPIC IN CLINICAL INTERVIEWS PROMPTED BY LEARNING DIFFICULTIES ${ }^{1}$
}

\author{
Michèle Grossen \& Denis Apothéloz
}

\section{Sensitive topics in clinical interviews}

The definition of intelligence, as everybody knows, has always been a controversial issue in psychology. Even scholars in this discipline do not agree upon a common definition and probably never will. An easy way to escape from this controversy is to take up Binet's famous joke "Intelligence is what my test measures". In fact, this pragmatic definition shows that intelligence is not only a scientific concept, it is also an historical and institutional construction which emerged through the use of cultural artifacts such as tests. Whatever "intelligence" is, it is now highly valued by our society and institutions. However, as research on the social representations of intelligence shows (Mugny \& Carugati 1985), there are still conflicting views on its "true" nature, not only in the scientific but also in the everyday world. The term intelligence has become established in our everyday discourse; it may be used to categorise people or actions, and thus has moral implications. Saying that someone is "intelligent" or "stupid" is not a mere description, but also a positive or negative judgement. "Intelligence" also belongs to the institutional discourse of education. In fact, institutional representatives (teachers, psychologists, etc.) may attribute school failure to a "lack of intelligence or abilities", as might the students and their parents. Thus, school failure and "intelligence" seem to be correlated not only in intelligence tests, but also in everyday and institutional discourse.

Among the various institutional contexts in which "intelligence" is discussed are counselling centres for children and adolescents, since many of the requests for help referred to them concern learning difficulties. Therapists working in these centres are expected to look for possible explanations for the child's difficulties and to propose an appropriate remedial measure. In Swiss counselling centres, a frequent procedure is a threestep routine consisting of: a) an initial interview with the parents (one or both of them), the referred child, sometimes his or her sisters or brothers, and the teacher or other relevant people from the child's social network; b) a psychological examination of the child; c) an interview in which the therapist gives the parents the results of the psychological examination and proposes remedial measures.

On an interpersonal level, this professional routine is a delicate social situation. In fact, the therapists have the authority (and the institutional obligation) firstly to make an

\footnotetext{
'This research received the financial support of the National Foundation for Scientific Research (credit $n^{\circ}$ 11-34261.92 attributed to Michèle Grossen). The authors would like to thank Anne-Marie Rifai who revised our first English draft.
} 
evaluation which would bring about a better understanding of the child's difficulties, and secondly to determine possible remedial measures. Any evaluation of the child inevitably includes amongst other things, an assessment of the child's "abilities" (or "intelligence"), namely a dimension of the child's identity ("intelligence") which has high social significance. In interviews prompted by learning difficulties, therapists are thus confronted with a dilemma between their professional obligation to act as experts assessing "intelligence", and a social obligation to respect rules (politeness rules in particular) which, in Goffmanian terms, do not threaten the clients' face.

This dilemma is not specific to counselling interviews prompted by learning difficulties. On the contrary, it is common to many types of clinical interview. For example, Peyrot's study (1987) which analysed client-counsellor interactions in a drug abuse treatment agency showed that these clinical interviews are characterised by what the author calls circumspection. Circumspection refers, on the one hand, to the strategies therapists use to avoid involving the client too personally in the definition of his or her problem and on the other, to the strategies deployed by the client in order to avoid being involved personally. One of the therapists' main circumspection strategies was the use of oblique references, the linguistic characteristics of which were: 1) first-person references (selfreferences by the therapist); 2) generic third-person references (such as "some people"); 3) indefinite pronouns (such as "one", or the non-deictic use of "you”). Peyrot showed that the use of oblique references had the advantage of protecting the addressee's face and of avoiding conflicts; its disadvantage was however that it could easily be ignored by the client. According to Peyrot, it was the specificity of the situation, namely the fact that the consultation was imposed on the clients by the criminal justice system that accounts for the use of oblique references. Our own interpretation is that the therapists were faced with a dilemma between their role (helping people vs. executing a criminal justice decision) and need to gain the client's cooperation in therapy. This dilemma resulted in the extensive use of face-work strategies, indirectness, and vagueness.

Bergmann's analysis of psychiatric intake interviews (1992) reached a similar conclusion. The author showed that the object which was referred to (namely the description of the patient's mental state or behaviour which prompted the consultation) was always treated with discretion; this discretion relied on the use of three types of descriptive practices: 1) litotes formulations (the psychiatrist used for example the expression "not so well" in order to describe the patient's mental state); 2) the use of mitigators; the psychiatrist said that the patient was "kind of irritated a little bit"; 3) the use of euphemisms (in this case, the reported event is described in a way which recasts it as quite ordinary behaviour; for example, "you withdrew very much in your flat" was a euphemistic formulation when compared with a later description of the same event ("you had barricaded yourself"). Hence, as in Peyrot's study, the need to protect the patient's positive identity led to indirectness and vagueness. According to Bergmann, the patient might have interpreted these descriptive practices either as a way of encouraging disclosure, or as a clue indicating that the behaviour being referred to was actually improper. Consequently, the discretion of the descriptive practice (or the face-work carried out by the psychiatrist) might paradoxically elicit the patient's suspicion that his or her behaviour was "abnormal".

In another study on topical sensitivity, Linell and Bredmar (1996) analysed 30 midwives' and expectant mothers' interactions in a preventative maternal health care unit 
in Sweden. The routine of the initial interview included the discussion on sensitive topics, namely lifestyle issue (the woman's smoking and drinking habits), tests for sexually transmitted diseases (syphilis, HIV) and amniosentisis test (an indicator of serious abnormality in the foetus). The results showed that the episodes pertaining to these three topics yielded eight features of indirectness and mitigation which can be interpreted as signs of sensitivity. A comparison between the three topics showed that the way they were treated had common features: A general preference for avoidance, a reluctance to give detailed accounts or to penetrate issues, anonymisation, understating the severity of potential abnormalities. There were however also differences, life-style issues being less sensitive than the other two. The authors' conclusion is similar to Bergmann's since they note that despite the neutral treatment of sensitive issues observed in their corpus, the issues remained sensitive and had moral implications which never completely disappeared. Again, vagueness, indirectness and mitigations characterised the treatment of sensitive topics.

Returning to the question of interviews prompted by learning difficulties, our assumption is that these situations require circumspection, since they deal with a highly valued quality, that is to say "intelligence". In fact, the parents (and maybe the child) know that the therapist might explain the child's difficulties by "a lack of intelligence", and the therapist knows that the parents know that this explanation might be given. Consequently, the therapist is very aware that the parents might not easily accept an explanation of this sort which could even cause a breakdown of the therapeutic alliance. Our assumption is supported by Maynard's studies on the delivery of a diagnosis concerning mental disabilities (Maynard 1989, 1991a, 1991b). His analysis of psychiatrist-parents interactions showed that the delivery of a diagnosis was accomplished through a routine (called Perspective Display Series) in which the psychiatrist elicited the parents' perspective before giving his or her own perspective regarding the child. It was thus an indirect method which, as Maynard showed, led to a better acceptance of the diagnosis and avoided emotional reactions on the part of the parents, as well as open conflicts between the doctor and the parents.

As a consequence, it could be expected that in initial interviews prompted by learning difficulties, therapists would avoid attributing the cause of the child's difficulties to a "lack of intelligence", and that the parents would avoid giving information that the therapists might interpret as an indication of a "lack of intelligence". Starting from this main assumption, we shall present the results of an analysis conducted on a series of initial clinical interviews prompted by learning difficulties. Our aim is firstly to explore whether the topic of "intelligence" is discussed in all or just some of the interviews and then to address the following main question: How is "intelligence" brought into language in this type of interview? Does the analysis of the corpus enable us to conclude that "intelligence" is a sensitive topic ${ }^{2}$ ?

After a presentation of the procedure used to isolate episodes referring to "intelligence", we shall present the results and show that these episodes have some characteristics in common with results obtained in previous research on sensitive topics, but pertain to an argumentative genre. This observation will lead us to claim that the way

\footnotetext{
${ }^{2}$ As we shall see, the term "topic" is taken in a generic way. In the sense adopted here, it does not imply that a given object of discourse is topicalised (for a discussion on the notion of "topic", see Mondada 1994).
} 
"intelligence" is discussed in these interviews is strongly dependent upon the conversational context and may thus be considered an object of discourse in the sense developed by Grize (1989).

\section{Procedure}

\subsection{Description of the corpus}

Our corpus is made up of 8 initial clinical interviews which took place at a local authority psychological consultation service for children and adolescents in two French speaking Swiss Cantons. All these interviews were prompted by learning difficulties and requested by the child's teachers with the parents' consent. One or two therapists, one or both parents, the referred child and, in some cases, his or her sister or brother, participated in the interview. The patients were six boys aged $6,8,13$ ( 2 boys) and 14 ( 2 boys), and two girls aged 13 and 15. The interviews, the length of which varied from 45 to 90 minutes, were audio- or videotaped and transcribed in accordance with the transcript conventions indicated in appendix 1.

\subsection{Method of analysis}

The first step of the analysis was to identify "references to intelligence", namely all the words and utterances which concerned the child's "abilities" or "intelligence". Here is an exhaustive list of what was categorised as "references to intelligence" (they are given in a generic form): "intelligence", "intelligent", "succeeding" (in an exam or in at task school), "to manage", "to be able", "not having too much difficulty of noncomprehension", "to have the ability" (to do something), "to read perfectly", "to be normal", "to know" (different things), "to use one's potential”, "having good marks", "going better" or "improving one's performance", "not being stupid", "forgetting at school what was known at home", "not being retarded". The utterances "Then it goes up again a little then suddenly it goes down and it comes back a little bit like that" (talking of school performance) and "He has difficulties depending upon the discipline but I think that is a little bit absent-minded" were also considered to be a reference to intelligence. As can be seen from this list, the term "reference to intelligence" is used in its broadest sense: In selecting the references to intelligence, we did not simply limit ourselves to utterances containing the term "intelligent". Let us however stress a linguistic property of the predicate "intelligent". In fact "intelligent", like other predicates such as "tall”, "good", "narrow", is a predicate which presupposes a gradation, and gradation, as Sapir (1944) showed, always implies a comparison, even when it is not explicitly formulated. On the contrary, predicates such as "alive", "unmarried" or "female" can in principle not be graded and if they are, their meaning changes, as in the example "I've never been so unmarried as I was last year". As a consequence, using a predicate like "intelligent" implies the existence of a norm, and this norm is object-related. For example, "intelligent" does not mean the same in the noun-phrases "this intelligent man", "this intelligent cat", or "this intelligent child".

The method used to isolate references to intelligence has the advantage of being 
based on linguistic clues enabling a comparison between the interviews. It has however two main drawbacks: It does not capture sequences in which the issue of "intelligence" is completly implicit (examples of this will be given below); it applies our own categories for what is to be considered to be "references to intelligence".

The second step of the analysis consisted of defining the sequences or episodes in which references to intelligence occurred. The aim was to include the context of the references to intelligence in order to analyse the conversational dynamics at work. The beginnings and ends of these episodes (which could include more than one reference to intelligence) were determined on the basis of opening and closing verbal and non verbal markers, for example a pause followed by a change of addressee, or a question involving a topic shift. Extract [1] gives an example of one of these episodes (in bold, the references to intelligence; TM is the male therapist; TW is the female therapist and $\mathrm{M}$ the mother).

\section{[1] (Gontrand, 207-223)}

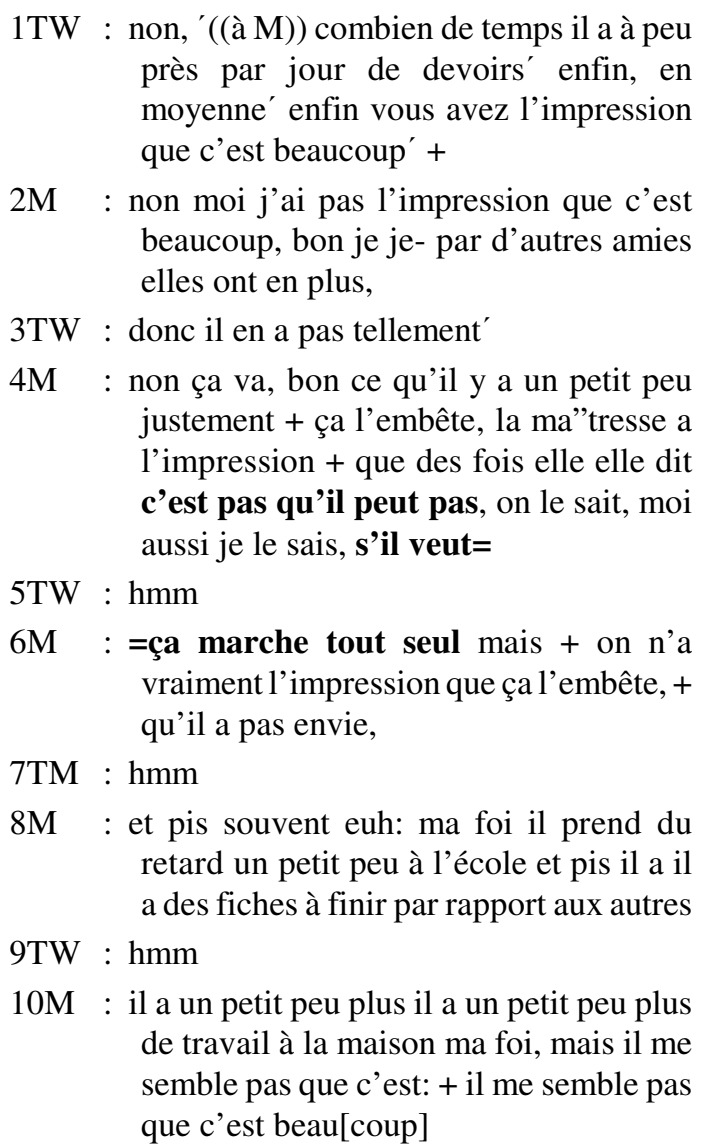

1TW : how much homework does he have in the evenings? well on average? well does it seem to you to be a lot?

2M : no it doesn't seem a lot to me, well I, I, [know] from other friends that they have more,

3TW : so he doesn't have a lot of homework?

$4 \mathrm{M}:$ no, it's ok, well that there's not much, that's just it happens + he gets bored, the teacher feels + that sometimes, she she says it's not that he can't, we know that, I know that too, if he wants=

5TW : hmm

$6 \mathrm{M}:=$ it's a breeze but + we really feel that he doesn't want to, + that he's not willing

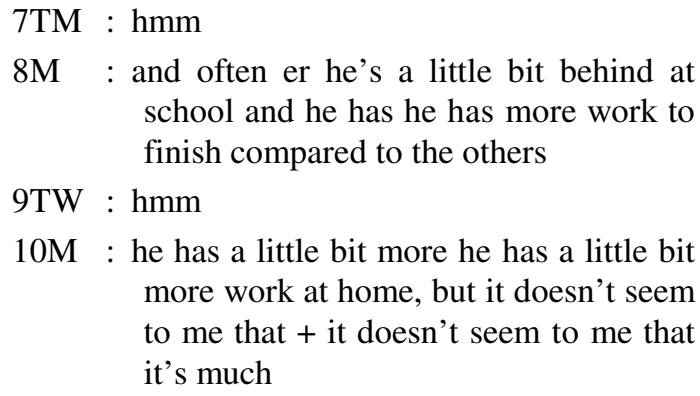
school and he has he has more work to finish compared to the others

9TW : hmm

$10 \mathrm{M}$ : he has a little bit more he has a little bit more work at home, but it doesn't seem to me that + it doesn't seem to me that it's much

\subsection{Questions}

Two specific series of questions will be addressed: 1) Do all participants refer to "intelligence" during the interview? Is there a variation in the frequency with which the participants mention this topic? 2) Do the sequences in which "intelligence" is mentioned 
have some specific linguistic features? If so, what are their common points?

\section{Results}

The results will be reported in two sections corresponding to the aforementioned questions: The first section will report the frequency of the references to intelligence; the second section will describe their linguistic characteristics.

\subsection{Frequency of the references to intelligence}

Do we find a reference to intelligence in all the interviews? Who are the participants who mention intelligence? Table 1, which indicates the frequency of the references to intelligence by participant in each interview, answers these questions.

Table 1: Frequency of the references to intelligence by participant in each interview

\begin{tabular}{|c|c|c|c|c|c|c|c|c|c|}
\hline $\begin{array}{l}\text { Interviews (Pseudonym } \\
\text { family name) }\end{array}$ & $\begin{array}{l}\text { Child's } \\
\text { gender }\end{array}$ & TW & $\mathrm{TM}$ & $\mathrm{F}$ & M & $\mathrm{C}$ & $\mathrm{P}+\mathrm{M}$ & $\begin{array}{c}\text { TW+ } \\
\text { M }\end{array}$ & $\mathrm{N}$ \\
\hline Jean AMBROISE & M & & 1 & & 1 & & & & 2 \\
\hline André BARNABE & $M$ & & & 3 & 4 & & 1 & & 8 \\
\hline André EDOUARD & $\mathrm{M}$ & & & & 4 & & & & 4 \\
\hline Dominique FRANCOIS & M & & & & 1 & & & & 1 \\
\hline Alain GONTRAND & $\mathrm{M}$ & 3 & & & 5 & & & 1 & 9 \\
\hline Alice HECTOR & $\mathrm{F}$ & & 2 & & 4 & 4 & & & 10 \\
\hline Bernard JULES & $\mathrm{M}$ & & & 6 & & & & & 6 \\
\hline Liliane KARL & $\mathrm{F}$ & & & & & & & & - \\
\hline $\mathbf{N}$ & & 3 & 3 & 9 & 19 & 4 & 1 & 1 & 40 \\
\hline
\end{tabular}

TW: therapist woman; TM: therapist man; F: father; M: mother; C: child; M: male; F: female. Screened cells indicate that the participant was not present.

Table 1 shows that all the interviews except one (Karl), contain at least one reference to intelligence. However, there are large variations between the interviews: In fact Barnabé's interview contain eight references to intelligence, while François' interview contains only one.

A closer look at Karl's interview, which involved a Portuguese family and their fifteen-year old daughter, Liliane, enables us to venture some explanation which could account for the absence of any reference to intelligence. In fact, during the whole interview, the girl refused to speak French in front of her parents, so her mother had to translate her daughter's discourse. It emerged that the girl had always been good at school and that her school difficulties were very recent. We can therefore make the hypothesis that the issue of "intelligence" did not need to be made explicit not only because the girl's former school experience testified to her abilities, but also because her behaviour during the interview led 
the therapist to interpret her school difficulties as the outcome of psycho-affective problems. This observation also shows the limits of our method since, as we mentioned before, it does not account for cases in which "intelligence" is discussed in a completely implicit way.

Table 1 also shows that among the 40 references to intelligence which could be identified, 29 were given by the parents, 6 by the therapists, 4 by a child (but it is always the same child in the Hector family) and one was co-uttered by the mother and the therapist. About three quarters of these mentions were thus due to a parent, while only one interview contained references to intelligence formulated by a child.

\subsection{Linguistic features of the references to intelligence}

Do the episodes containing one or more references to intelligence have specific linguistic features? In response to this question, the analysis showed five linguistic features: The use of reported speech and other-reformulations; evaluative assertions; the formulation of two opposite terms; exemplary narratives; the explicit reference to a norm. Let us examine them.

\subsubsection{The use of reported speech and other-reformulations}

A comparison between the parents' and the therapists' references to intelligence showed that their linguistic features were different.

Among the 29 references to intelligence formulated by a parent, 11 used reported speech. Among the latter, nine quoted the teacher's discourse and two quoted an "expert" (without any specification) and a "psychologist". Extract [2] gives an example of a piece of reported speech quoting the teacher's discourse (in bold, the reference to intelligence; italics, the marker of reported speech):

[2] (Gontrand, 346-417)

\footnotetext{
$1 \mathrm{M}$ : il y a des choses par exemple si: il lui arrive une injustice, vraiment quelque chose qui est pas juste il peut se mettre dans un état euh: il est très sensible, $l a$ maîtresse aussi me le dit d'ailleurs

2TW : hmm

3M : c'est fou ce qu'il est sensible, ce qu'elle me dit aussi par rapport aux autres enfants + même justement il a- bon elle elle ce qu'elle pense en fait ce qu'elle $m$ 'a dit c'est pas qu'il arrive pas, c'est qu'il veut pas,

4TW : hmm
}

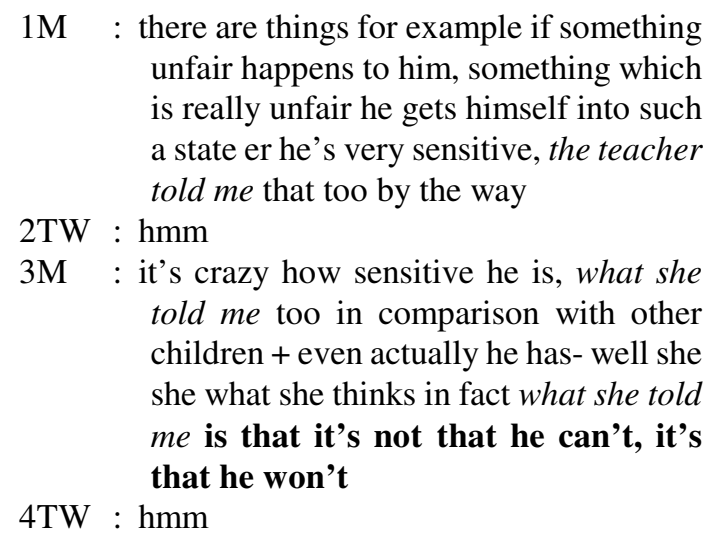
unfair happens to him, something which is really unfair he gets himself into such a state er he's very sensitive, the teacher told me that too by the way told me too in comparison with other children + even actually he has- well she she what she thinks in fact what she told $m e$ is that it's not that he can't, it's that he won't

4TW : hmm

Three different but not exclusive interpretations may account for this observation: A first interpretation is that reporting the discourse of an institutional representative (the 
teacher) gives more weight to what could be considered to be the parent's own opinion, namely that their child is "intelligent". In other words, the parents use reported speech as a convincing and authoritative argument for their child's "intelligence". A second interpretation is that by using reported speech, the parents avoided priding themselves on having an "intelligent" child and avoided overtly defending their own interests. The use of reported speech would thus be a face-work strategy. A third interpretation is inspired by Grize (1996) who writes that: "One of the most important characteristics of argumentation is its ability to hide behind its finality" (p. 19, our translation) and states that it is, for example, often far more effective to speak of someone with respect rather than declaring him to be a great man and enumerating his qualities. Similarly, it might be said that if the aim of the parents' discourse was to argue that their child was "intelligent", reported speech had the advantage of making this aim less visible; or, to put it better, it might be said that anticipating that their "reference to intelligence" might be interpreted as an argument by the therapist, the parents' use of reported speech somehow disguises the argument being presented.

As regards the therapists' six references to intelligence, five of them were reformulations of the parent's discourse ${ }^{3}$, as illustrated in extract [3]. Note that one of the sources of this reformulation can be found in extract [2].

[3] (Gontrand, 980-1023) (in bold: the reference to intelligence; underlined: the reformulation)

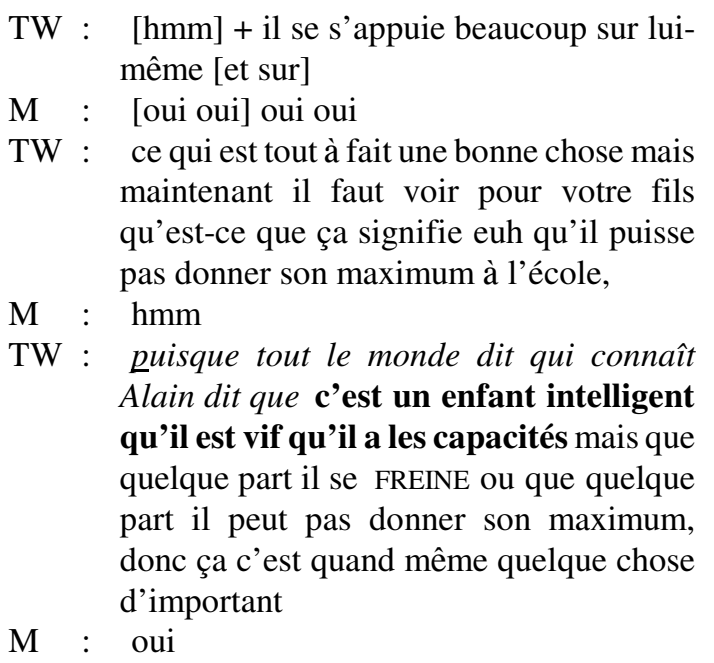

TW : $[\mathrm{hmm}]+$ he relies much on himself [and on]

M: : [yes yes] yes yes

TW : which is a good thing absolutely but now we have to see what it means huh that for your son err that he can't give of his best at school,

$\mathrm{M}: \mathrm{hmm}$

TW : since everybody who knows Alain says that he's an intelligent child that he's clever that he has the ability but that somehow he HOLDS himself back or that somehow he cannot give his best, so that that's nevertheless something IMPORTANT

M : yes

The sources of the five other-reformulations which were identified were a reference to intelligence made by parents, except in one case. This means that the therapists never introduced the topic of "intelligence" themselves. This extended reformulation of the parent's discourse on the part of the therapists shows that the therapists avoided taking the

${ }^{3}$ This observation is congruent with other studies showing that other-reformulations are more frequent in the therapists' than in the clients' discourse (Apothéloz \& Grossen 1996; Grossen \& Apothéloz 1996). 
responsibility of their own discourse. A possible interpretation of this is that in so doing, they did not risk troubling their relationship or, in more technical terms, the therapeutic alliance.

Before continuing, let us take a closer look at the only interview in which a therapist introduced the topic of intelligence. In this case (which has been analysed in detail in Grossen 1996), the parents explained their child's difficulties by a long series of psychological explanations. After their account, the first reformulation made by the therapist is a reference to intelligence (extract [4]):

[4] (Ambroise, 494-506)

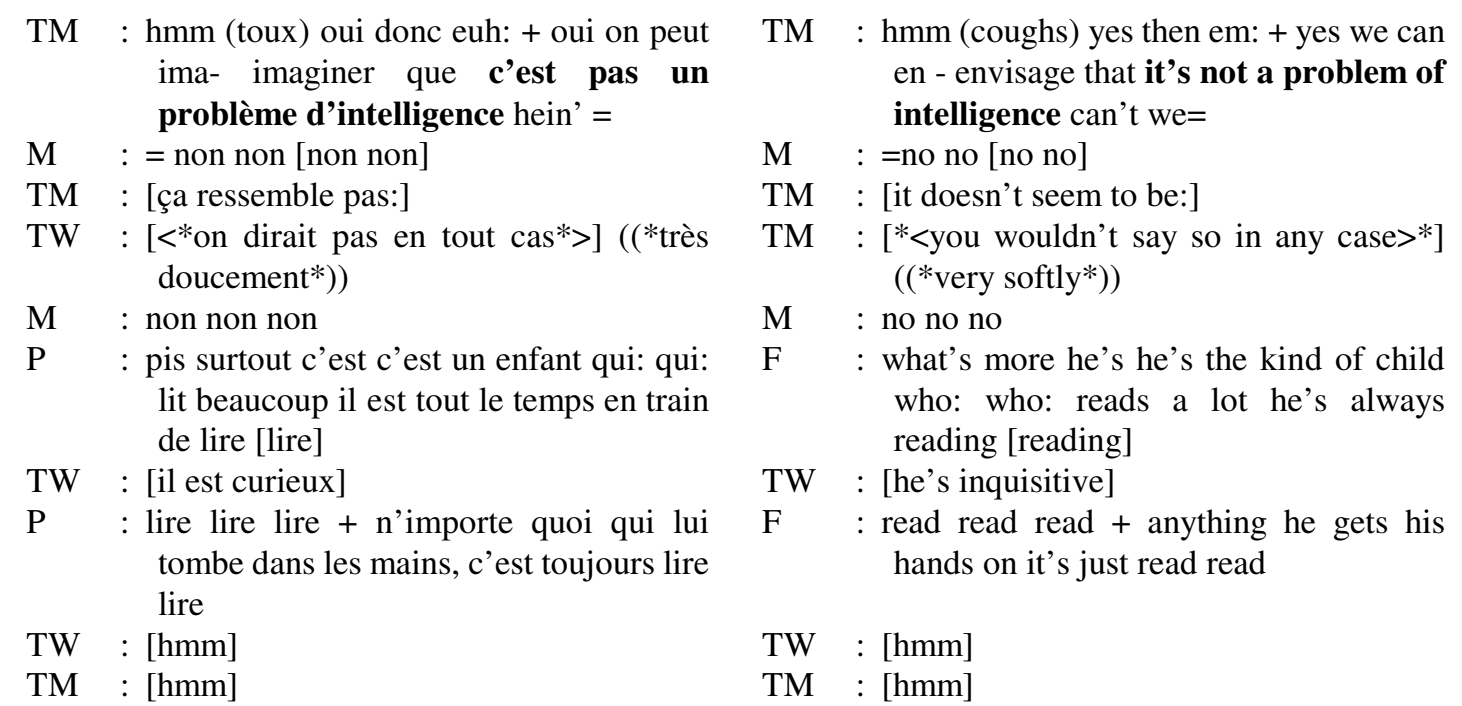

TM's reformulation is introduced by the marker "then" and has many sources in the parents' discourse. However, none of these sources explicitly mentioned the child's "intelligence". This observation suggests that the topics which have been previouly discussed enabled the therapist to exclude the hypothesis of a "lack of intelligence". In this particular case, the fact that the child's psycho-affective state was discussed at length seems to have orientated the therapist's interpretation towards other possible causes (for an analysis of the whole of Ambroise's interview, see Grossen 1996).

\subsubsection{The use of evaluative assertions}

A second linguistic feature of the episodes is that all of them contained evaluative assertions, namely assertive utterances which accomplish an evaluation. An example of this can be found in extract [1] (6M), when the mother says: "When he wants to, it's a breeze". Let us stress that references to intelligence using formulations, such as "intelligent" or "able" are evaluative assertions by the mere fact that they are, as previously stated in the introduction, grading predicates. 


\subsubsection{The formulation of opposite terms}

In all the interviews, there was at least one reference to intelligence opposing two competing formulations of the child's difficulties: On the one hand a formulation of the child's "competence" or "intelligence", on the other a formulation of his or her "lack of competence", or of a possible explanation for his or her difficulties:

- "stupidity" vs. "mental block" ("bêtise” vs. "blocage”)

[5] M: je pense pas que c'est de lbêtise ou:: pour M : I don't think it's stupidity or + for me moi c'est peut-être plus un:: je sais pas it's maybe more a me I don't know a moi un problème de blocage dans la tête problem of mental block

(Hector, 164-165)

- "normality” vs. "mental block” ("normalité" vs. "blocage”)

[6] M: elle m'a dit qu'il était tout à fait normal M : She [the teacher] told me that he was mais il était bloqué un peu (François, perfectly normal but that he had a bit a 169-171) mental block

- “intelligence" vs. "maturity” ("intelligence” vs. "maturité”)

[7] M: peut-être mûre pour son âge + elle n'est M : maybe mature for her age + she's not pas trop mais autrement je pense question very but otherwise I think that as far as intelligence elle est là (Hector, 940-942) intelligence goes she's up there

- "intelligence" vs. “attention" ("intelligence”vs. "attention")

[8] M: l'intelligence serait là théoriquement mais $M \quad$ : the intelligence is there theoretically but l'attention n'y est pas (Barnabé, 591- the attention isn't 593)

- "having ability" vs. "having difficulties" ("être capable "vs. "avoir de la peine")

[9] M: il est capable, + mais euh ++ il a de la M : he's capable + but er ++ he has some peine (Edouard, 6-7) difficulties

- "to be able” vs. "to be willing to" “( "pouvoir" vs. "vouloir")

[10] M: c'est pas qu'il arrive pas c'est qu'il veut M : it's not that he can't it's that he won't pas (Gontrand, 372-373)

Other oppositions concerned the circumstances in which the child "uses" his or her "intelligence", for example "at home" vs. "at school".

- "at home" vs. "at school”

[11] C: quand je vais à la maison j' arrive bien pis dès que j'arrive à l'école ben je sais pas, je pense à quelque chose d'autre ou je me concentre pas assez je sais pas (Hector, 88-90)

C : when get home, I can do it well and as soon as I get to school well I don't know, I think of something else or I don't concentrate enough I don't know 
In addition, a closer analysis of these episodes showed that:

a) 28 references to intelligence (among 40) contained markers such as "but", "since", "nevertheless", "it's not that"; these markers can be considered as indicators of the polyphony (or multivoicedness) which characterises the participants' discourse. Extracts [8] and [10] can also be considered as refutating a possible "lack" of "maturity", "intelligence" or "competence".

b) 13 references to intelligence contained an attitude verb, such as "I think that", "I believe that", "I don't know whether", or other locutions indicating that the speaker takes the responsibility (or the authorship) for his or her own discourse, such as "in my opinion", "as far as I am concerned". These 13 references to intelligence are all given by a parent. Extract [12] gives an example:

[12] (Hector, 163-164)

M : (...) elle n'est PAS PLUS B ÊTE QU'UNE AUTRE ça j'en suis sûre je lui ai déjà dit d'ailleurs, je pense pas que c'est de la bêtise (...)
M : (...) she's not MORE STUPID THAN SOMEONE ELSE I'm sure of that what's more I have already told her, I don't think it's stupidity

c) 20 references to intelligence also contained quantifiers such as " $a$ lot", "much", "not at all", "better", "a little", etc.;

d) 11 references to intelligence contained argumentative conjunctions, such as "because", "since".

All the episodes contained at least one of the latter four characteristics, some of them contained several. Only four references to intelligence (two formulated by a parent and two formulated by the child in Hector's family) did not contain any of these features.

The formulation of opposite terms, as well as these four characteristics, can all be considered as clues indicating the fundamentally argumentative and/or explicative orientation of the parents' discourse (on the characteristics of argumentation and explanation, see for example Apothéloz \& Brandt 1992; Apothéloz, Brandt \& Quiroz 1993). To summarise: References to intelligence were generally introduced by a parent and the way they were brought up and discussed during the interview suggests that essentially the parents' hidden agenda was to argue that their child was intelligent and to give arguments against other possible voices (or counter-arguments in Billig's terms; see Billig 1987).

\subsubsection{Exemplary narratives}

Two examples of what we call "exemplary narratives" were found in our corpus. Both were parents' narratives. Extract [13] is one of them. In this extract, the mother's discourse has the typical "once upon a time" structure. It is thus the description of a remarkable past event followed by a narrative complication, in this case the fact that the child could do something he is usually unable to do. The interesting point in this narrative is that it provides not only a description of, but also an explanation for the child's "inability to read". It is also based 
upon an opposition such as those described in the preceding section; in this case, the opposition is between what usually happens (namely that the child is unable to read) and what happened when the mother got angry (namely that the child was able to read). The mother's narrative appears thus to be an implicit argumentation in favour of his abilities: If the child could show even one single time that he could read, this provides the proof that his difficulties were not due to a lack of ability.

[13] (Edouard, 456-501)

M : (...) une fois où je me suis énervée j’ai remarqué que la fois où je m'étais énervée alors là il savait tout, ce que d'habitude il ne fait pas, alors là il savait lire sans buter sur les mots, il savait lire parfaitement
M : (...) once when I got angry I noticed that the time I got angry then he knew everything, when usually he doesn't, then he could read without stumbling on the words, he could read perfectly

\subsubsection{Explicit reference to a norm}

In five episodes (all mentioned by a parent), we observed that the parents made an explicit reference to a norm when describing their child. They compared him or her with children of the same age (with respect to qualities such as "ability", "sensitivity", "maturity") and remarked upon conformity (as in extract [14]) or non-conformity (as in extract [15]).

[14] (Gontrand, 697-745)

M : (...) je lui ((= au prof. de tennis de son fils)) en ai parlé ce matin pis il m'a dit oui mais tu sais avec les enfants de cet âge, il le voit aussi puisqu'il en a aussi des des pas des si petits mais quand [même]

[15] (Hector, 934-946)

M : et elle a elle a parfois des réactions qui sont pas des réactions d'une enfant qui va bientôt avoir treize ans
M : I told him (the son's tennis teacher) about it this morning and he told me yes but you know with children of this age, he sees it too because he has chilren of that age too not so small but all the same

M : and she sometimes has reactions that are not those of a child who will soon be thirteen

Other examples of a reference of non-conformity to a norm may be found above in extracts [2] (turn 2M) and [8].

\section{Discussion}

The aim of this study was to analyse how a concept as highly valued as "intelligence" is 
brought into language in initial interviews prompted by learning difficulties. Considering firstly the frequency of references to intelligence, we found that in all the interviews of our corpus, except for one there was at least one reference to intelligence, and that these were mostly made by the parents. We then examined whether the episodes in which "intelligence" was mentioned had specific linguistic features and found that this was actually the case: in about one third of the cases, the parents used reported speech while mentioning intelligence and referred to the discourse of an institutional representative (mostly the teacher). As regards the therapists, they always (apart from one instance) reformulated the parent's reference to intelligence and consequently were not directly responsible for introducing the topic of "intelligence". The other linguistic characteristics which were observed (evaluative assertions; formulation of two opposite terms, presence of attitude verbs, refutation utterances, argumentative conjunctions, or quantifiers; exemplary narratives; explicit references to a norm) showed that the parents' discourse pertained to an argumentative and explicative genre and included different voices which implicitly claimed an opposite view of possible causes of learning difficulties. The precautions the parents took when they brought their child's situation into language was another sign of this multivoicedness.

These results confirm the intuition which guided our study: "Intelligence" (whatever it is!) is a sensitive topic, namely a topic which cannot be raised directly and needs to be handled with care. The analysis of our corpus showed that both the parents and the therapists seemed to avoid attributing the child's "problem" to a "lack of intelligence". Of course, this does not mean that they did so for the same reasons. In fact, it might be suggested that the therapists tended to avoid an interpretation of this sort for reasons which were linked on the one hand to the necessity of creating a therapeutic alliance with the parents and on the other to the absence, in the institutional context, of remedial measures for a "lack of intelligence". As regards the parents, they might have at least two reasons for avoiding a "lack of intelligence" explanation: Avoiding a label which has strong moral implications for their child's identity and for their own identity as parents; avoiding unwanted decisions that the therapists, as gatekeepers, could take (for example a change of orientation in their child's educational career). However despite these differences, it seems that for the parents, as well as for the therapists, psychological causes (namely psychoaffective "problems", relational "problems", or even "adolescence" considered as a difficult life time, etc.) might be ideal candidates for explaining the child's difficulties. In our opinion, it might be primarily because psychological explanations are widespread in everyday life and hence may be expected to create an intersubjective state; secondly, and more probably, because from the parents' and therapists' perspectives psychological explanations enter the therapists' field of competence, they can be expected to be treated.

\section{Conclusion}

The results of this study are in line with previous studies on sensitive topics and circumspection (in particular Bergmann 1992; Linell \& Bredmar 1996; Peyrot 1987) which showed that indirectness is a common conversational device used to talk about sensitive topics. However, these studies concerned sensitive topics which were part of an institutional routine and had to be introduced by the institutional representatives. Thus, 
indirectness and vagueness were characteristics of the institutional representative's discourse. By contrast, in our corpus, "intelligence" and other related topics were not topics which were part of an institutional routine. Determining the child's "level of intelligence" was probably part of the therapist's hidden agenda, but the analysis of our corpus did not reveal any formal clue to confirm this hypothesis (or the knowledge we have of this type of institutional context). However, our analysis showed that this agenda was certainly attributed to the therapists by the parents. The parents, by anticipating possible explanations they thought the therapists would invoke, in fact imputed theories and intentions onto the therapists. In other words, the parents' discourse revealed that they had theories about the therapists' mental processes.

The latter statement raises a new issue which concerns the ontological status of the parent's discourse. In fact, it could be claimed that by imputing theories to the therapists, the parents also revealed or put their own theories on stage for us as analysts. The few extracts reported in this article might be sufficient to suggest that the parents' discourse was based upon what some scholars would call social representations of intelligence, development and learning (Mugny \& Carugati 1985; see also Carugati, Emiliani \& Molinari 1990). In our opinion however, such an interpretation is highly questionable since it tends to see discourse as a reflection of the mind and to neglect that discourse is always contextualised to a given activity and also recipient oriented. According to our own assumptions on language, the references to intelligence which were identified in our corpus are better considered as "objects of discourse"/schematisation in the sense defined by Grize (1989), namely a semiotic fiction which is applied to contingent and context-bound finalities.

This interpretation does not of course mean that the participants did not rely on some stable cognitions or on some pre-existing knowledge which might be labelled with terms such as ground-rules (Mercer 1995), metacontracts (Rommetveit 1976), commonality (Marková, Graumann \& Foppa 1995), or "cultural preconstructs" (Grize 1996). But considering the participants' alignment in the course of the conversation as the outcome of internal (all be it social) representations would be too reductive and rely on an acontextual view of both language and cognition.

\section{References}

Apothéloz, D. \& P.-Y. Brandt (1992) Relation d'étayage: Justification et/ou explication? Travaux du Centre de Recherches Sémiologiques 60: 55-88. Neuchâtel: Université de Neuchâtel, Centre de Recherches Sémiologiques.

Apothéloz, D., P.-Y. Brandt \& G. Quiroz (1993) The function of negation in argumentation. Journal of Pragmatics 19: 23-38.

Apothéloz, D. \& M. Grossen (1996) Dynamique conversationnelle dans un entretien psychothérapeutique: Analyse des reformulations. Interaction \& Cognitions 1.1: 115-149.

Bergmann, J. (1989) Veiled morality: Notes on discretion in psychiatry. In P. Drew \& J. Heritage (eds.), Talk at work: Social interaction in institutional settings Cambridge: Cambridge University Press, pp. 137-162.

Billig, M. (1987) Arguing and thinking. Cambridge: Cambridge University Press. 
Carugati, F., F. Emiliani \& L. Molinari (1990) Being a mother is not enough: Theories and images in the social representations of childhood. Revue Internationale de Psychologie Sociale 3.3: 289-306.

Grize, J.-B. (1989) The objects of discourse: Connexity and opposition. In M.-E. Conte, S. Petöfi \& E. Sözer (eds.), Text and Discourse Connectedness. Amsterdam: John Benjamins, pp. 137-162.

Grize, J.-B. (1996) Logique naturelle et communications. Paris: Presses Universitaires de France.

Grossen, M. (1996) Counselling and gatekeeping: Definitions of the problem and situation in a first therapeutic interview. Text 16.2: 161-198.

Grossen, M. \& D. Apothéloz (1996) Communicating about communication in a therapeutic interviekwurnal of Language and Social Psychology 15.2: 101-132.

Linell, P. \& M. Bredmar (1996) Reconstructing topical sensitivity: Aspects of face-work in talks between midwives and expectant mothers. Research on Language and Social Interaction 29.4: 347-379.

Marková, I., C. Graumann \& K. Foppa (eds.) (1995) Mutualities in dialogue. Cambridge: Cambridge University Press.

Maynard, D.W. (1991a) On the interactional and institutional bases of asymmetry in clinical discourse. American Journal of Sociology 97.2: 448-495.

Maynard, D.W. (1991b) The perspective-display series and the delivery and receipt of diagnosis news. In D. Boden \& H. Zimmerman (eds.), Talk and social structures. Cambridge: Polity Press, pp. 164-192.

Maynard, D. W. (1989) Notes on the reception of diagnostic news regarding mental disabilities. In T. Anderson, A.J. Meehan \& A. Rawls (eds.), New directions in sociology. New York: Irvington, pp. 54-67.

Mercer, N. (1995) The guided construction of knowledge. Talk amongst teachers and learners. London: Multilingual Matters.

Mondada, L. (1994). Verbalisation de l'espace et fabrication du savoir: Approche linguistique de la construction des objets de discours. Doctoral dissertation. Lausanne (Switzerland): University of Lausanne.

Mugny, G. \& F. Carugati (1985) L'intelligence au pluriel. Cousset (CH): Delval.

Peyrot, M. (1987) Circumspection in psychotherapy: Structures and strategies of client-counselor interaction. Semiotica 65: 249-268.

Rommetveit, R. (1976) On the architecture of intersubjectivity. In L.H. Strickland, K.J. Gergen, \& F.J. Aboud (eds.), Social psychology in transition. New York: Plenum Press, pp. 163-175.

Sapir, E. (1944) Grading: A study in semantics. Philosophy of Science 2: 122-149.

\section{Appendix 1: Transcript conventions}

Overlaps

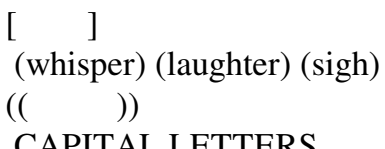

Laughter, telephone rings, voice, whisper, etc.:

Transcriber's comment:

Accentuation of a word or a syllable:

CAPITAL LETTERS

Intonation markers

': rising intonation (not necessarily a question)

, : falling intonation 
Pauses

$$
\begin{array}{ll}
+ & (1 \mathrm{sec}) \\
++ & (2 \mathrm{sec})
\end{array}
$$

Stretch of syllables

$$
\text { : } \quad:: \quad::
$$

Unintelligible syllables

$\mathrm{x}$ : one syllable unintelligible

xx: two syllables unintelligible

No gap between two turns (latching) end of turn 1: = beginning of turn 2: =

Interruption by the speaker him/herself or by the hearer: 